\title{
Cardiopulmonary Functions and Aerobic Capacity in Patients with Systemic Sclerosis
}

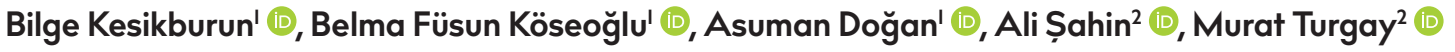 \\ 'Cardiopulmonary Rehabilitation Unit, Ministry of Health, Ankara Physical Medicine and Rehabilitation Training and Research Hospital, \\ Ankara, Turkey \\ ${ }^{2}$ Department of Rheumatology, Ankara University School of Medicine, Ankara, Turkey \\ ORCID IDs of the authors: B.K. 0000-000I-6IIO-2252; B.F.K. 0000-0002-3463-009X; A.D. 0000-000I-5448-I995; A.Ș. 0000-0002-6953- \\ 4276; M.T. 0000-000I-5302-4485.
}

\author{
Cite this article as: Kesikburun B, Köseoğlu BF, Doğan A, Șahin A, Turgay M. Cardiopulmonary Functions and Aerobic Capacity in \\ Patients with Systemic Sclerosis. Cyprus J Med Sci 2019; 4(2): 84-9.
}

\section{BACKGROUND/AIMS}

Systemic sclerosis (SSc) is a chronic inflammatory multisystem disorder characterized by microvascular damage and extensive fibrosis. Cardiopulmonary involvement is strongly associated with the severity of the disease itself and the mortality and morbidity of SSc. The aim of this study was to evaluate cardiopulmonary functions and aerobic capacity of SSc patients through cardiopulmonary exercise testing and compare them to healthy individuals.

\section{MATERIAL and METHODS}

A total of 27 patients ( 25 females, 2 males; mean age $43.96 \pm 13.01$ years; mean body mass index $26.34 \pm 5.33 \mathrm{~kg} / \mathrm{m}^{2}$ ) who were diagnosed with SSc according to the American Rheumatism Association criteria and a control group of 23 healthy age-matched individuals (I8 females, 5 males; mean age $42.04 \pm 12.28$ years; mean body mass index $26.89 \pm 3.99 \mathrm{~kg} / \mathrm{m}^{2}$ ) were included in the study. All subjects underwent a treadmill cardiopulmonary exercise test. A computerized gas analysis system collected and analyzed expired gases during the exercise.

\section{RESULTS}

The mean peak oxygen consumptions were significantly decreased in the patient group $(14.09 \pm 6.24 \mathrm{~mL} / \mathrm{kg} / \mathrm{minute})$ as compared to the control group $(19.65 \pm 5.97 \mathrm{~mL} / \mathrm{kg} /$ minute) $(p=0.002)$. In addition, the patient group had significantly lower peak minute ventilation ( $p=0.011)$, $\mathrm{O}_{2}$ pulse $(p=0.003)$, and exercise time ( $\left.p=0.027\right)$, while having higher VD/VT rest and VD/VT peak in comparison with the control group.

\section{CONCLUSION}

The results of this study showed that patients with SSc had a lower aerobic capacity as compared to healthy individuals. The cardiopulmonary exercise test is a useful tool to detect exercise intolerance and provide additional information on the mechanism of exercise limitation in SSc.

Keywords: Systemic sclerosis, cardiopulmonary function, exercise test, exercise capacity

\section{INTRODUCTION}

Systemic sclerosis (SSc) is a chronic inflammatory multisystem disorder characterized by microvascular damage and extensive fibrosis. The disease not only affects the skin but also damages multiple internal organs such as the lungs, kidneys, heart, and gastrointestinal tract. Organ involvement most often occurs early in the course of SSc, especially in the first 5 years (I). Cardiopulmonary involvement comprises interstitial pneumonia, pulmonary hypertension, conduction system defects, pericardial effusion and myocardial ischemia, hypertrophy, or failure of the cardiovascular system (2). Cardiopulmonary involvement was found to be strongly associated with the severity of the disease itself and the mortality and morbidity of SSc (3).

Exercise capacity is an independent, long-term predictor of mortality from cardiovascular disease in healthy individuals (4). The cardiopulmonary exercise test (CPET) is a useful tool in the evaluation of undiagnosed exercise intolerance of patients with respiratory and/or cardiovascular disease, functional work capacity, response to treatment following surgery, rehabilitation or pharmacological treatment, and in the detection of gas exchange abnormalities and determination of potential exercise-limiting factors (5). 
Of the reasons responsible for low exercise capacity and dyspnea in patients with SSc, cardiopulmonary impairment is more important than cutaneous lesions, chronic inflammation, and deconditioning $(6,7)$. The determination of exercise capacity is crucial to detect early cardiopulmonary impairment in patients with SSc. The aim of this study was to evaluate cardiopulmonary functions and aerobic capacity through CPET in patients with SSc compared to healthy individuals.

\section{MATERIALS and METHODS}

\section{Patients}

A total of 27 patients ( 25 females, 2 males; mean age $43.96 \pm 13.01$ years; mean body mass index (BMI) $26.34 \pm 5.33 \mathrm{~kg} / \mathrm{m}^{2}$ ) diagnosed as having SSc according to the American College of Rheumatology (ACR) criteria (8) and a control group of 23 healthy age-matched individuals ( 18 females, 5 males; mean age $42.04 \pm 12.28$ years; mean BMl $26.89 \pm 3.99 \mathrm{~kg} / \mathrm{m}^{2}$ ) were included in the study. All patients were recruited from the Ankara University School of Medicine, Department of Rheumatology. Patients with either diffuse systemic sclerosis $(n=8$, $29.6 \%)$ or limited scleroderma $(n=19,70.4 \%)$ were included in the study. The consenting subjects were interviewed and put through a complete medical assessment, which included a detailed medical history and routine laboratory measurements in addition to a physical examination, before participating in the study. The inclusion criteria were: (I) age of $\geq 18$ years, (2) SSc as defined by the ACR classification criteria, (3) being ambulatory and able to perform walking treadmill exercise, and (4) no previous history of any regular exercise training or sporting activity. Patients were excluded if they had: (I) unstable angina, (2) severe arterial hypertension at rest (>200/120 mmHg), (3) uncontrolled heart failure, (4) uncontrolled arrhythmia, (5) severe mental impairment, (6) high degree AV block, and (7) significant pulmonary hypertension or orthopedic impairment. The study protocol was approved by the Local Research Ethics Committee of Ankara Physical Medicine and Rehabilitation Training and Research Hospital. The study adhered to the guidelines of the Declaration of Helsinki and informed consent was obtained from all participants.

\section{Cardiopulmonary Exercise Testing (CPET)}

All subjects performed a treadmill CPET after a resting spirometric measurement. A computerized gas analysis system collected and analyzed expired gases during exercise (Sensormedix, CA, USA). A standard open-circuit method was used to collect expired gases. It was calibrated with known gas concentrations and volumes prior to each test. The system consisted of a mask, a two-way breathing valve, a rolling seal spirometer, an oxygen analyzer, and a carbon dioxide analyzer. The breathing apparatus was attached to the mask after placing it on the subject's face. Heart rate and electrocardiogram were displayed throughout the CPET. Capillary oxygen tension was measured on an oxygen photometer attached to the earlobe. A modified Bruce protocol was used (9), which protocol had fixed increments in speed and inclines every 3 minutes. The initial 3-minute stage occurred at a speed of $2.74 \mathrm{~km} /$ hour and a $0 \%$ gradient. The second and third stages had the same speed and duration but the gradients were increased by $5 \%$ and $10 \%$, respectively. Each subsequent stage had an increment of $1.29 \mathrm{~km} /$ hour in speed and $2 \%$ in gradient. The criteria for termination of CPET included chest pain suggestive of angina, ischemic electrocardiogram changes, complex ectopy or $2^{\text {nd }}$ or $3^{\text {rd }}$ degree atrioventricular block, a >20 mmHg drop in systolic blood pressure from the highest value during the test, hypertension (systolic blood pressure > $250 \mathrm{mmHg}$; diastolic blood pressure $>120 \mathrm{mmHg}$ ), severe desaturation, oxygen saturation $\left(\mathrm{SaO}_{2}\right) \leq 80 \%$ with accompanying symptoms and signs of hypoxemia, loss of coordination, and mental confusion (I0).

Oxygen consumption $\left(\mathrm{VO}_{2}\right)$, carbon dioxide exhaled $\left(\mathrm{VCO}_{2}\right)$, minute ventilation $(V E)$, respiratory rate $(R R)$, respiratory exchange ratio (RER), the ratio of physiological dead space to tidal volume (VD/VT), the ventilatory equivalent for $\mathrm{VCO}_{2}$ (VE/ $\mathrm{VCO}_{2}$ ), and $\mathrm{SaO}_{2}$, were recorded for every breath during CPET. The anaerobic threshold was determined with a computerized $\checkmark$-slope method of gas exchange data.

\section{Overview of Procedures}

Baseline characteristics including age, gender, body mass index (BMI), smoking habit, duration of disease, type of SSc, and comorbidities were recorded. The patients were tested with an echocardiogram and an electrocardiogram. Pulmonary hypertension was assessed by recording pulmonary artery systolic pressure (PASP) and a value of to $25 \mathrm{mmHg}$ at rest was accepted as normal (II). The findings of chest $x$-ray and high-resolution computerized tomography (HRCT) were also noted from medical records.

\section{Statistical Analysis}

Statistical analysis was performed using Statistical Package for the Social Sciences for Mac, Version 20.0 software (IBM Corp.; Armonk, NY, USA). The data were stated as mean \pm standard deviation for continuous variables and as proportions for categorical variables. The Chi-square test was applied for comparison of proportions. The Student's t-test was used to compare the mean values of continuous variables between the groups. If the distribution of the continuous variables was not normal, the Mann-Whitney test was used for comparison. A value of $p<0.05$ was accepted as statistically significant.

\section{RESULTS}

The baseline characteristics of the patients and the healthy individuals are presented in Table I. There were no differences between the groups in terms of age, gender, and BMI. The mean duration of the disease was $4.87 \pm 4.69$ years. A total of $19(70.4 \%)$ patients had limited cutaneous SSc and the rest (eight patients, $29.6 \%$ ) had diffuse SSc. Cardiac abnormalities were detected in the echocardiograms of II (40.9\%) patients (Table 2). Five (18.6\%) of the patients had a PASP value of over $25 \mathrm{mmHg}$, while six patients (22.2\%) had significant interstitial lung disease based on HRCT and chest $x$-ray findings.

Cardiopulmonary values obtained at maximum exercise are presented in Table 3. CPET was terminated due to generalized muscle fatigue in 14 patients, dyspnea in five patients, desaturation in two patients, and blood pressure criteria in two patients. In the control group, the test was terminated due to generalized muscle fatigue in 19 control subjects, dyspnea in two subjects, and blood pressure criteria in two subjects. There was no significant difference in the blood pressure measurements between the two groups at baseline and at peak exercise ( $p>0.05)$. Sig- 


\begin{tabular}{|c|c|c|c|}
\hline & $\begin{array}{l}\text { Patient Group } \\
\quad(n=27)\end{array}$ & $\begin{array}{c}\text { Control Group } \\
\qquad(n=23)\end{array}$ & $p$ \\
\hline Age (years)* & $43.96 \pm 13.01$ & $42.04 \pm 12.28$ & 0.596 \\
\hline Gender (female/male) & $25 / 2(92.6 / 7.4)$ & $18 / 5(78.3 / 21.7)$ & 0.145 \\
\hline $\operatorname{BMI}\left(\mathrm{kg} / \mathrm{m}^{2}\right)^{*}$ & $26.34 \pm 5.33$ & $26.89 \pm 3.99$ & 0.686 \\
\hline Smoking habit & & & 0.182 \\
\hline Non-smoker & $16(59.3 \%)$ & $19(82.8 \%)$ & \\
\hline Current smoker & $7(25.9)$ & $2(8.6 \%)$ & \\
\hline Ex-smoker & $4(14.8)$ & $2(8.6 \%)$ & \\
\hline Duration of disease (years) & $4.87 \pm 4.69$ & & \\
\hline \multicolumn{4}{|l|}{ Type of SSc } \\
\hline Limited cutaneous (IcSSC) & $19(70.4 \%)$ & & \\
\hline Diffuse cutaneous (dcSSc) & $8(29.6 \%)$ & & \\
\hline \multicolumn{4}{|l|}{ Comorbidities } \\
\hline Arterial hypertension & $5(18.5 \%)$ & & \\
\hline Diabetes mellitus & $3(11.1 \%)$ & & \\
\hline Cardiovascular Disease & $2(7.4 \%)$ & & \\
\hline Hypothyroidism & $3(11.1 \%)$ & & \\
\hline Other & $5(18.5)$ & & \\
\hline
\end{tabular}

*Mean \pm standard deviation

BMI: Body Mass Index; SSc: Systemic Sclerosis

TABLE 2. Cardiac findings of the patients with SSc $(n=27)$

\section{Echocardiogram}

$\begin{array}{lc}\text { Normal } & 16(59.1 \%) \\ \text { TR } & 7(25.9 \%) \\ \text { MR } & 2(7.4 \%) \\ \text { MS } & 1(3.7 \%) \\ \text { Pericardial effusion } & 1(3.7 \%) \\ \text { Mean PASP }(\mathrm{mmHg})^{*} & 24.9 \pm 5.3 \\ \text { PASP }>25 \mathrm{mmHg} & 5(18.6 \%) \\ \text { PASP } \leq 25 \mathrm{mmHg} & 22(81.4 \%) \\ \text { Electrocardiogram } & \\ \text { Normal } & 22(81.5 \%) \\ \text { Tachycardia } & 3(11.1 \%) \\ \text { Bradycardia } & 2(7.4 \%)\end{array}$

TR: tricuspid regurgitation; MR: mitral regurgitation; MS: mitral stenosis; PASP: pulmonary arterial systolic pressure

nificant electrocardiographic ST-segment changes indicating a positive test were obtained in four patients during the CPET. $\mathrm{SaO}_{2}$ was $<88 \%$ in two patients at rest and dropped by $>4 \%$, i.e., it dropped to $<88 \%$ and desaturation developed in II patients during the CPET. At the peak exercise, the values of $\mathrm{VO}_{2^{\prime}} \mathrm{VE}$ peak, $\mathrm{O}_{2}$ pulse, and exercise time were significantly lower and VD/VT rest and peak were significantly higher in the patient group than in the control group. Normal anaerobic threshold responses were determined in two patients (at a level $\geq 40 \%$ of the predicted $\mathrm{VO}_{2 \mathrm{~m}} \mathrm{ax}$ ). In 25 of 27 patients, no anaerobic threshold was identified.

\begin{tabular}{|c|c|c|c|}
\hline & $\begin{array}{l}\text { Patient Group } \\
(n=27)\end{array}$ & $\begin{array}{c}\text { Control Group } \\
(n=23)\end{array}$ & $p$ \\
\hline $\mathrm{VO}_{2}$ peak $(\mathrm{mL} / \mathrm{kg} / \mathrm{min})$ & $14.09 \pm 6.24$ & $19.65 \pm 5.97$ & 0.002 \\
\hline $\mathrm{VO}_{2}$ peak $(\mathrm{L} / \mathrm{min})$ & $0.94 \pm 0.38$ & $1.35 \pm 0.43$ & 0.001 \\
\hline $\mathrm{O}_{2}$ pulse $(\mathrm{mL} /$ beat $)$ & $5.94 \pm 2.38$ & $8.16 \pm 2.62$ & 0.003 \\
\hline HR peak (bpm) & $158.33 \pm 26.07$ & $167.57 \pm 22.05$ & 0.187 \\
\hline VE peak (L/min) & $55.57 \pm 21.43$ & $71.26 \pm 20.20$ & 0.011 \\
\hline RR (bpm) & $41.29 \pm 10.43$ & $38.82 \pm 7.49$ & 0.349 \\
\hline HRR & $|3.4| \pm 28.16$ & $4.39 \pm 21.75$ & 0.218 \\
\hline $\mathrm{BR}(\mathrm{VE} \max / \mathrm{MV} \vee \%)$ & $72.07 \pm 27.06$ & $72.26 \pm 18.61$ & 0.977 \\
\hline VD/VT rest & $0.56 \pm 0.06$ & $0.47 \pm 0.053$ & $<0.001$ \\
\hline VD/VT peak & $0.31 \pm 0.08$ & $0.23 \pm 0.06$ & $<0.001$ \\
\hline RER & $1.4 \mid \pm 0.17$ & $1.47 \pm 0.17$ & 0.233 \\
\hline $\mathrm{SaO}_{2}(\%)$ & $92.41 \pm 2.91$ & $92.74 \pm 2.97$ & 0.693 \\
\hline $\mathrm{SaO}_{2}$ end $(\%)$ & $87.0 \pm 4.48$ & $87.74 \pm 4.01$ & 0.542 \\
\hline Exercise time (min) & II. $46 \pm 4.22$ & $13.81 \pm 3.19$ & 0.027 \\
\hline $\begin{array}{l}\text { SBP/DBP }(\mathrm{mm} \mathrm{Hg}) \\
\text { rest }\end{array}$ & $112.5 \pm 18.93 / 77.7 \pm 10.5$ & $117.8 \pm \mid 3.1 / 78.2 \pm 10.2$ & 0.207 \\
\hline $\begin{array}{l}\text { SBP/DBP }(\mathrm{mm} \mathrm{Hg}) \\
\text { peak }\end{array}$ & $|55.9 \pm 39.1 / 87.0 \pm 1| .7$ & $159.5 \pm 24.7 / 90.0 \pm 11.2$ & 0.702 \\
\hline \multicolumn{4}{|c|}{$\begin{array}{l}\text { *Mean } \pm \text { standard deviation. } \\
\mathrm{VO}_{2} \text {; oxygen consumption; } \mathrm{HR} \text {; heart rate; } \mathrm{VE} \text {; minute ventilation; } \mathrm{RR} ; \\
\text { respiratory rate; bpm; beat per minute; } \mathrm{HRR} \text {; heart rate reserve; } \mathrm{VD} / \mathrm{VT} \text {; } \\
\text { the ratio of physiological dead space to tidal volume; RER; respiratory } \\
\text { exchange ratio; SaO2; oxygen saturation; SBP; systolic blood pressure; } \\
\text { DBP; diastolic blood pressure }\end{array}$} \\
\hline
\end{tabular}

\section{DISCUSSION}

The present study evaluated cardiopulmonary functions and aerobic capacity using CPET in SSc. The results showed that the values of $\mathrm{VO}_{2}$ peak, $\mathrm{VE}$ peak, $\mathrm{O}_{2}$ pulse, and exercise time were significantly lower and VD/VT values at rest and peak were significantly higher in patients with SSc as compared to healthy individuals. Poor cardiopulmonary findings were revealed in patients with SSc.

The identification of patients with cardiopulmonary complications is challenging even with the use of specific investigations in SSc patients (12). Resting pulmonary and cardiac function testing cannot exactly reflect exercise performance and functional capacity. The 6-minute walk test (6MWT) is a practical simple test but it does not provide peak oxygen uptake, diagnose the cause of dyspnea on exertion, or evaluate the causes or mechanisms of exercise limitation (I3). However, CPET allows the detection of organ involvement in asymptomatic patients without cardiopulmonary involvement. In a study by Alkotob (14), it was shown that early pulmonary vascular pathology could be determined using CPET in asymptomatic SSc patients without cardiopulmonary involvement. CPET may also be used in SSc patients with multisystem involvement to globally assess the exercise response in the pulmonary, cardiovascular, hematopoietic, neuropsychological, and skeletal muscle systems.

Oxygen consumption peak has been traditionally identified as the major indicator of aerobic capacity and fitness. This is 
calculated from the difference between the volume of $\mathrm{O}_{2}$ in the inhaled and exhaled air during exercise per unit of time (I5). A reduced $\mathrm{VO}_{2}$ peak represents reduced exercise capacity. Normal values are $\geq 85 \%$ predicted (16). Similar to previous studies, the present study result showed exercise capacity impairment in the patients with SSc, evidenced by a significantly decreased $\mathrm{VO}$, peak value (17-19). This value was significantly lower in the patient group as compared to the control group. Although cardiopulmonary involvement is the main culprit for reduced exercise limitation in SSc, a sedentary lifestyle, fatigue, and articular and skin deformities may also contribute to exercise intolerance. Oliveira et al. (19) found a mean $\mathrm{VO}_{2}$ peak value of $19.8 \mathrm{ml} / \mathrm{kg} /$ minute in patients with SSc, while the mean $\mathrm{VO}_{2}$ peak was 14.9 $\mathrm{mL} / \mathrm{kg} /$ minute in the current study. This value was reported by Plazak et al. (20) as $16.5 \mathrm{~mL} / \mathrm{kg} /$ minute. The difference could be attributed to the fact that Oliveira et al. (19) investigated exercise capacity especially in SSc patients without pulmonary involvement, which indicates that pulmonary involvement is a major contributing factor for lower exercise capacity. Also, the shorter exercise time is an indicator of exercise capacity impairment. In the present study, the patient group had a significantly shorter exercise time as compared to the control group. CPET can be used to comprehensively evaluate exercise capacity and cardiopulmonary involvement in patients with SSc and aerobic exercise programs can be considered in the treatment of patients who have reduced exercise capacity.

Minute ventilation is the volume of air exhaled from the lungs in I minute. $V E_{\max }$ is the maximal ventilation achieved during exercise and it represents ventilator demand (I5). Abnormality in $V E_{\max }$ can reflect respiratory and neuromuscular limitation to exercise. There are few data related to $V E_{\max }$ achieved in patients with SSc. In a study by Rosato et al. (2I), it was reported that patients with SSc had a lower VE $E_{\max }$ level as compared to the healthy individuals, which was similar to the results of the present study. This finding might be interpreted as a respiratory limitation to exercise.

$\mathrm{O}_{2}$ pulse $\left(\mathrm{VO}_{2} / \mathrm{HR}\right)$ is the amount of oxygen consumed by the tissue per heartbeat. It is calculated by dividing $\mathrm{VO}_{2}$ by $\mathrm{HR}$ and is expressed as $\mathrm{mL} /$ beat. Reduced $\mathrm{O}_{2}$ pulse can indicate decondition, cardiopulmonary disease, and early exercise limitation due to ventilator restriction (16). Normality is defined as $>80 \%$. The current study findings showed that the patients had a lower $\mathrm{O}_{2}$ pulse level compared to the control group. Sudduth et al. (18) and Plazak et al. (20) investigated exercise capacity in patients with SSc using CPET and both those studies also found a lower level $\mathrm{O}_{2}$ pulse in the patient groups than in the control groups.

Respiratory exchange ratio is obtained from the ratio of $\mathrm{VCO}_{2} /$ $\mathrm{VO}_{2}$ and corresponds to the gas exchange ratio. RER is the best non-invasive indicator for the level of exercise during the performed CPET. A peak value of $\geq 1$.l is widely accepted as a marker of maximal exercise effort (22). If the patient does not reach this value, other limiting factors apart from cardiac dysfunction should be considered. In the current study, only two patients did not reach the peak value of RER, with the mean RER value determined as $1.41 \pm 0.17$. Moreover, in the comparison of the two groups, no difference was determined with respect to the RER peak value. Similarly, Rosato et al. (2I) found no difference in the RER peak valve of SSc patients when compared with a healthy control group.
Ratio of physiological dead space to tidal volume is one of the indicators of the adequacy or efficiency of gas exchange. An elevated VD/VT or absence of a reduction in VD/ VT with exercise suggests the presence of a pulmonary vascular disease such as pulmonary hypertension (I5). In a study by Schwaiblmair et al. (23), 78 patients with SSc had increased VD/VT during exercise, which was comparable with the current study. These findings suggested that gas exchange abnormality in SSc patients is a common problem.

Desaturation is regarded as any decrease in oxygen saturation measured by standard pulse oximetry $\left(\mathrm{SpO}_{2}\right)$ of $4 \%$ or more, or to a nadir of $88 \%$ or less, regardless of the baseline $\mathrm{SpO}_{2}(24)$. Desaturation is common in patients with interstitial lung disease, pulmonary hypertension, and chronic obstructive disease (22). Exercise-induced oxygen desaturation is one of the predominant factors contributing to exercise limitation in patients with SSc. Desaturation during the exercise test is also associated with high mortality risk and increased severity of disease (25, 26). In the present study, $\mathrm{SaO}_{2}$ was below $88 \%$ in two patients at rest and it dropped by $>\% 4$, following which it dropped below $88 \%$ and desaturation developed in II patients during the CPET. Thus, desaturation developed in a total of 13 patients. Similar to these findings, in a study by Ciurzyński et al. (27) that evaluated left and right ventricular diastolic function in patients with systemic sclerosis, a higher rate of desaturation was seen in the patient group as compared to the control group. This desaturation seen during the exercise test provides prognostic information about the patients with SSc.

Respiratory rate is the number of breathing cycles per minute. It reflects abnormalities in the mechanics of breathing, control of breathing, and/or hypoxemia or psychological disorders. The normal value of RR as $<60$ breaths per minute is during peak exercise time. A normal value of $\mathrm{RR}$ of $<60$ breaths per minute is 34 during peak exercise time. In the current study, three patients had a value of $>60$ breaths/minute. Rapid and shallow breathing resulting in a high RR may be evidence of inefficient ventilation in systemic sclerosis. To the best of our knowledge, there has been no study in literature that has evaluated the value of $\mathrm{RR}$ in SSc to date.

Ventilatory equivalent for $\mathrm{VCO}_{2}$ is a good non-invasive estimator of inefficient ventilation (28). The normal value is <34 and higher values reflect increased dead space ventilation or hyperventilation during exercise. In addition, $\vee \mathrm{E} / \mathrm{VCO}_{2}$ has been shown to be a predictor of mortality in patients with pulmonary arterial hypertension and chronic heart failure (29). Sudduth et al. (I8) revealed that higher $\mathrm{VE} / \mathrm{VCO}_{2}$ is indirectly related with early pulmonary vasculopathy. The current study results showed one patient with a higher value. The study conducted by Rosato et al. (2I) showed that VE $/ \mathrm{VCO}_{2}$ correlated with vascular involvement and SSc severity in patients without cardiopulmonary involvement. Therefore, $\mathrm{VE} / \mathrm{VCO}_{2}$ is an important value which should be considered when evaluate cardiopulmonary involvement in SSc patients.

The present study achieved the goals that it aimed to substantiate. However, there were some limitations. First, healthy individuals were not assessed with HRCT, echocardiogram, and chest $x$-ray. Unnecessary radiation exposure was avoided be- 
cause doing so might have caused an ethical violation as these individuals did not have any pulmonary symptom. The second limitation is the cross-sectional design of the study. Further prospective researches that assess CPET over a longer period of time will better define the development of cardiopulmonary impairment in patients with SSc.

A comprehensive evaluation of all CPET variables can provide clinicians with more information on the mechanism of exercise limitation, prognosis, and mortality risk. Cardiopulmonary involvement most often occurs in the course of SSc, especially in the first 5 years. CPET can be applied for the detection of cardiopulmonary abnormalities not revealed by routine testing. In addition, the ability to detect cardiopulmonary involvement using CPET combined with advanced treatment options may prevent mortality and organ-based complications of SSc. If abnormalities are established, ventilatory exercise and aerobic training programs can be considered to improve the aerobic capacity of SSC patients.

Ethics Committee Approval: Ethics committee approval was received for this study from Ankara Physical Medicine and Rehabilitation Training and Research Hospital. (Approval Date: 07.01.2013, Approval Number: 4.06.23.34-902/III).

Informed Consent: Informed consent was obtained from the patients who participated in this study.

Peer-review: Externally peer-reviewed.

Author contributions: Concept - B.F.K., A.D., B.K.; Design - B.F.K., A.D.; Supervision - M.T., B.F.K.; Resource - A.Ș., B.K., A.D.; Materials - A.Ș., B.K., A.D.; Data Collection and/or Processing - B.K., B.F.K., A.D.; Analysis and/ or Interpretation - B.K., B.F.K.; Literature Search B.K., A.Ș.; Writing - B.K., B.F.K.; Critical Reviews - B.F.K., M.T.

Conflict of Interest: The authors have no conflicts of interest to declare.

Financial Disclosure: The authors declared that this study has received no financial support.

\section{REFERENCES}

I. Steen VD, Medsger TA Jr. Severe organ involvement in systemic sclerosis with diffuse scleroderma. Arthritis Rheum 2000; 43: 243744. [CrossRef]

2. Kahan A, Coghlan G, McLaughlin V. Cardiac complications of systemic sclerosis. Rheumatology (Oxford) 2009; 48: iii45-8. [CrossRef]

3. Elhai M, Meune C, Avouac J, Kahan A, Allanore Y. Trends in mortality in patients with systemic sclerosis over 40 years: a systematic review and meta-analysis of cohort studies. Rheumatology (Oxford) 2012; 5I: 1017-26. [CrossRef]

4. Ekelund LG, Haskell WL, Johnson JL, Whaley FS, Criqui MH, Sheps DS. Physical fitness as a predictor of cardiovascular mortality in asymptomatic North American men. The Lipid Research Clinics Mortality Follow-up Study. N Engl J Med 1988; 24: I379-84. [CrossRef]

5. AdultCardiopulmonary Exercise Testing. Available from: URL: https:// www.health.qld.gov.au/_data/assets/pdf_file/0023/147515/qhgdl-958.pdf.

6. Blom-Bülow B, Jonson B, Baver K. Factors limiting exercise performance in progressive systemic sclerosis. Semin Arthritis Rheum 1983; 13: 174-8I. [CrossRef]

7. Boutou AK, Pitsiou GG, Siakka P, Dimitroulas T, Paspala A, Sourla E, et al. Phenotyping Exercise Limitation in Systemic Sclerosis: The Use of Cardiopulmonary Exercise Testing. Respiration 2016; 91: II5-23. [CrossRef]
8. Subcommittee for Scleroderma Criteria of the American Rheumatism Association Diagnostic and Therapeutic Criteria Committee. Preliminary criteria for the classification of systemic sclerosis (scleroderma). Arthritis Rheum 1980; 23: 581-90. [CrossRef]

9. Bruce RA, Cooper MN, Gey GO, Fisher LD, Peterson DR. Variations in responses to maximal exercise in health and in cardiovascular disease. Angiology 1973; 24: 691-702. [CrossRef]

10. American Thoracic Society, American College of Chest Physicians. ATS/ACCP Statement on Cardiopulmonary Exercise Testing. Am J Respir Crit Care Med 2003; 167: 211-77. [CrossRef]

II. Khanna D, Clements PJ, Furst DE, Chon Y, Elashoff R, Roth MD, et al Correlation of the degree of dyspnea with health-related quality of life, functional abilities, and diffusing capacity for carbon monoxide in patients with systemic sclerosis and active alveolitis: results from the Scleroderma Lung Study. Arthritis Rheum 2005; 52 : 592-600. [CrossRef]

12. Arakkal G, Chintagunta SR, Chandika V, Damarla SV, Manchala S, Kumar BU. Cardio-pulmonary involvement in systemic sclerosis: A study at a tertiary care center. Indian J Dermatol Venereol Leprol 2017; 83: 677-82. [CrossRef]

13. ATS Committee on Proficiency Standards for Clinical Pulmonary Function Laboratories. ATS statement: guidelines for the six-minute walk test. Am J Respir Crit Care Med 2002; 166: III-7. [CrossRef]

14. Alkotob ML, Soltani P, Sheatt MA, Katsetos MC, Rothfield N, Hager WD, et al. Reduced exercise capacity and stress induces pulmonary hypertension in patients with scleroderma. Chest 2006; 130: 176-81. [CrossRef]

15. Datta D, Normandin E, ZuWallack R. Cardiopulmonary exercise testing in the assessment of exertional dyspnea. Ann Thorac Med 2015; 10: 77-86. [CrossRef]

16. American Thoracic Society; American College of Chest Physicians. ATS/ACCP Statement on cardiopulmonary exercise testing. Am J Respir Crit Care Med 2003; 167: 211-77. [CrossRef]

17. Morelli S, Ferrante L, Sgreccia A, Eleuteri ML, Perrone C, De Marzio $P$, et al. Pulmonary hypertension is associated with impaired exercise performance in patients with systemic sclerosis. Scand J Rheumatol 2000; 29: 236-42. [CrossRef]

18. Sudduth CD, Strange C, Cook WR, Miller KS, Baumann M, Collop $N A$, et al. Failure of the circulatory system limits exercise performance in patients with systemic sclerosis. Am J Med 1993; 95: 4138. [CrossRef]

19. de Oliveira NC, dos Santos Sabbag LM, Ueno LM, de Souza RB, Borges $C L$, de Sá Pinto AL, et al. Reduced exercise capacity in systemic sclerosis patients without pulmonary involvement. Scand J Rheumatol 2007; 36: 458-61. [CrossRef]

20. Płazak W, Heród P, Drapisz S, Tomkiewicz-Pajak L, Wrzosek J, Musiał $J$, et al. Influence of disease-related heart pathology on peak oxygen uptake and ventilation/carbon dioxide output ratio in systemic sclerosis and systemic lupus erythematosus patients (RCD code: I-3C). Journal of Rare Cardiovascular Diseases 2013; I: 96-102. [CrossRef]

21. Rosato E, Romaniello A, Magrì D, Bonini M, Sardo L, Gigante A, et al. Exercise tolerance in systemic sclerosis patients without pulmonary impairment: correlation with clinical variables. Clin Exp Rheumatol 2014; 32: 103-8.

22. Guazzi $M$, Adams $\vee$, Conraads $\vee$, Halle $M$, Mezzani $A$, Vanhees $L$, et al. EACPR; AHA. EACPR/AHA Joint Scientific Statement. Clinical recommendations for cardiopulmonary exercise testing data assessment in specific patient populations. Eur Heart J 2012; 33: 291727. [CrossRef]

23. Schwaiblmair M, Behr J, Fruhmann G. Cardiorespiratory responses to incremental exercise in patients with systemic sclerosis. Chest 1996; II0: 1520-5. [CrossRef]

24. Joshi JM, Gothi D. Routine use of pulse oximetry in out-patient department. Indian J Chest Dis Allied Sci 2009; 5I: 5-6.

25. Harris-Eze AO, Sridhar G, Clemens RE, Gallagher CG, Marciniuk DD. Oxygen improves maximal exercise performance in interstitial lung disease. Am J Respir Crit Care Med 1994; 150: 1616-22. [CrossRef] 
26. Villalba WO, Sampaio-Barros PD, Pereira MC, Cerqueira EM, Leme CA Jr, Marques-Neto JF, et al. Six-minute walk test for the evaluation of pulmonary disease severity in scleroderma patients. Chest 2007; |3|: 217-22. [CrossRef]

27. Ciurzyński M, Bienias P, Lichodziejewska B, Szewczyk A, Glińska-Wielochowska M, Jankowski K, et al. Assessment of left and right ventricular diastolic function in patients with systemic sclerosis. Kardiol Pol 2008; 66: 269-76.
28. Weisman IM, Zeballos RJ. An Integrative Approach to the Interpretation of Cardiopulmonary Exercise Testing Clinical Exercise Testing. Prog Respir Res 2002; 32: 300-22. [CrossRef]

29. Ponikowski P, Francis DP, Piepoli MF, Davies LC, Chua TP, Davos CH, et al. Enhanced ventilatory response to exercise in patients with chronic heart failure and preserved exercise tolerance: marker of abnormal cardiorespiratory reflex control and predictor of poor prognosis. Circulation 200I; 103: 967-72. [CrossRef] 